\title{
Post-Menopausal Vaginal Hemorrhage Related to the Use of a Hop-Containing Phytotherapeutic Product
}

\author{
Florence van Hunsel ${ }^{1}$ - Sonja van de Koppel $^{1} \cdot$ Eugène van Puijenbroek $^{1,2}$
}

Published online: 9 September 2015

(C) The Author(s) 2015. This article is published with open access at Springerlink.com

\begin{abstract}
Two 54-year-old women developed abdominal cramps and vaginal hemorrhage as a result of endometrial hyperplasia during treatment with a hop-containing phytotherapeutic product $\left(\mathrm{MenoCool}^{\circledR}\right)$ for post-menopausal complaints. The women used the hop-containing phytotherapeutic product $(418 \mathrm{mg}$ of hop per tablet) twice daily ( 1 and 0.5 tablets by both patient $\mathrm{A}$ and B). Patient A developed abdominal cramps and vaginal hemorrhage after 2 months of use. After gynecological examination, she was diagnosed with endometrial hyperplasia. The patient was treated with a curettage. The hop-containing phytotherapeutic product was discontinued, and the patient recovered. Patient B developed abdominal pain/cramps and vaginal hemorrhage after 5 months of use. A cervix smear, internal examination, and ultrasound were performed. Due to the thickness of the endometrium, a pipelle endometrial biopsy was performed. Results showed no indication for cervix cancer. The use of MenoCool ${ }^{\circledR}$ was ceased; follow-up information received from the patient shortly thereafter indicated that she had almost entirely recovered from the abdominal pain/cramps and vaginal hemorrhage. Hop (Humulus lupulus) has phytoestrogenic properties that may be the cause of endometrial hyperplasia and subsequent vaginal hemorrhage. A Naranjo assessment score of 5 was obtained for both cases, indicating a probable relationship
\end{abstract}

Florence van Hunsel

f.vanhunsel@lareb.nl

1 Netherlands Pharmacovigilance Centre Lareb, Goudsbloemvallei 7, $5237 \mathrm{MH}$ 's Hertogenbosch, The Netherlands

2 Department of Pharmacy, Pharmacotherapy and Pharmaceutical Care, University of Groningen, Groningen, The Netherlands between the patient's endometrial proliferation and subsequent vaginal hemorrhage and their use of the suspect drug.

\section{Key Points}

Many women use natural health products for relief of menopausal symptoms and perceive these products as safe.

Phytotherapeutic products for menopausal complaints can contain plants with phytoestrogenic properties.

The use of phytoestrogens can be related to endometrial hyperplasia and subsequent vaginal hemorrhage.

\section{Introduction}

Several treatment options exist for the treatment of menopausal symptoms in women. The use of hormonereplacement therapy (HRT) has decreased substantially after publication of the Women's Health Initiative (WHI) trial in 2002 [1-3]. Many post-menopausal women often perceive phytoestrogens in food supplements as a safer alternative than HRT [2], because these products are 'natural'. The use of these products is widespread [4].

Phytoestrogens represent a diverse group of non-steroidal natural products that have some estrogenic effects and are often marketed as food supplements [2]. Phytoestrogens are secondary metabolites that can mimic or 
modulate the actions of endogenous estrogens, usually by binding to estrogen receptors (ERs) [2]. The three major classes of phytoestrogens found in typical human diets are isoflavones (such as genistein and daidzein), which are concentrated in soybeans and soy products, but are also found in other legumes; lignans, which are distributed in seeds, whole grains, berries, fruit, vegetables, and nuts; and coumestans, which are found in broccoli and sprouts [2]. The flavonoid substance 8-prenylnaringenin (hopein) in hop also has phytoestrogenic properties. Of all phytoestrogens, 8-prenylnaringenin has the strongest ER activity $[5,6]$.

In the period from November 2011 to April 2015, the Netherlands Pharmacovigilance Centre Lareb received seven reports of vaginal hemorrhage caused by endometrial hyperplasia related to the use of the same hop-containing phytotherapeutic product $\left(\mathrm{MenoCool}^{\circledR}\right)$. The first three cases were reported by the same gynecologist and published in a Dutch medical journal in 2012 [7]. Since then, Lareb has received four more cases concerning the same association: two from gynecologists from different hospitals in the Netherlands and two directly from a patient. These last reports, received directly from patients, are described below.

\section{Case Reports}

Patient A, a 54-year-old woman (weight $79 \mathrm{~kg}$, height 177 $\mathrm{cm}$, body mass index [BMI] $25.2 \mathrm{~kg} / \mathrm{m}^{2}$ ) had been using the phytotherapeutic product $\mathrm{MenoCool}^{\circledR}$ (two times daily; morning one tablet, evening 0.5 tablet per oral administration) for the indication hot flushes and vaginal dryness due to the menopause. She had bought the product online through the manufacturer's website (http://www.menocool. $\mathrm{nl})$. The patient had not previously used the suspected drug. At that time, she had not menstruated for 2 years but had experienced hot flushes for approximately 4 years. The patient had never had an abnormal cervix smear, except a Pap III result 20 years previously. However, a repeated smear test showed no abnormalities. She had no medical history of vaginal bleeding, endometrial hyperplasia, endometrial polyps, or uterine leiomyomas. Her concomitant medication consisted of fexofenadine $120 \mathrm{mg}$ once daily and mometasone $50 \mu \mathrm{g} /$ dosage nasal inhalation spray, both since 2005. The patient started using MenoCool ${ }^{\circledR}$ in April 2014. After using MenoCool ${ }^{\circledR}$ for 2 months, the patient started to experience abdominal cramps and vaginal hemorrhage. These complaints were diagnosed by a gynecologist as related to a high proliferation of the endometrium. The patient was hospitalized for a day and underwent a curettage. After the curettage, the patient went for a follow-up appointment to her gynecologist and a significant increase in the endometrium was found again. The patient was treated with a course of norethisterone. Norethisterone has been effective in the treatment of dysfunctional uterine bleeding in patients with a proliferative or hyperplastic endometrium [8] and, as expected, the patient had a heavy withdrawal bleeding following withdrawal of norethisterone that lasted for several days. The following control appointment showed proliferation of the endometrium again but still within the normal range; this time no action was deemed necessary. According to the patient, the gynecologist in the hospital had no explanation for the rapid and extreme growth of the endometrium. The patient ceased the use of the phytotherapeutic product in September 2014 and had fully recovered by the time follow-up information was received by the pharmacovigilance center in February 2015. After a consultation in a women's health clinic, the patient was told by another gynecologist that she should not use drugs against hot flushes containing phytoestrogens to prevent a repeat of her complaints. Her endometrium was diagnosed at this clinic as thick but within the normal range, and there has been no hyperplasia of the endometrium or vaginal bleeding since.

Patient B, a 54-year-old woman (weight $70 \mathrm{~kg}$, height $176 \mathrm{~cm}$, BMI $\left.22.6 \mathrm{~kg} / \mathrm{m}^{2}\right)$, had been using MenoCool ${ }^{\circledR}(1.5$ tablets daily) for the indication hot flushes due to the menopause. She also bought the product online, through the same website as patient A. The patient had not previously used the suspected drug. She had not menstruated for 5 years. Her concomitant medication consisted of another supplement from the same manufacturer: MenoCool Extra oral lyophilisate ${ }^{\circledR}$ (2 tablets daily) containing a non-estrogenic flavone extract $22 \mathrm{mg}$, vitamin $\mathrm{D}_{3} 5 \mu \mathrm{g}$, biotine 25 $\mu \mathrm{g}$. In addition, she had been using alendronic acid $70 \mathrm{mg}$ once weekly since 2012. The patient started using MenoCool $^{\circledR}$ in October 2014. The MenoCool Extra oral lyophilisate ${ }^{\circledR}$ was added shortly after the start of $\mathrm{MenoCool}^{\circledR}$, following the advice of the manufacturer, because the patient experienced abdominal pain/cramps. After 5 months using this combination, the patient experienced vaginal hemorrhage. She was referred by her general practitioner to a gynecologist. A cervix smear, internal examination, and ultrasound were performed. Due to the thickness of the endometrium, a pipelle endometrial biopsy was performed. Results showed no indication for cervix cancer. The use of MenoCool ${ }^{\circledR}$ was ceased on 2 April 2015; on 13 April 2015 follow-up information received from the patient indicated that she had almost entirely recovered from the abdominal pain/cramps and vaginal hemorrhage.

According to the product's manufacturer (Standby Vital $\mathrm{BV}$, based in the Netherlands), the phytotherapeutic product MenoCool ${ }^{\circledR}$ consists of a combination of three kinds of hops (Humulus lupulus) selected for their flavonoid 
Table 1 Ingredients of the product MenoCool ${ }^{\circledR}$ as described by the manufacturer (tablet weight $1010 \mathrm{mg}$ )

\begin{tabular}{lc}
\hline Ingredients & Percentage \\
\hline Hop (Humulus lupulus) & 41.40 \\
Dietary fiber & 9.90 \\
Buckwheat (Fagopyrum esculentum) & 8.48 \\
Black oats (Avena sativa) & 8.48 \\
Malt (Semen hordei vulgaris germinatum) & 8.48 \\
Rye (Secale cereale) & 4.24 \\
Barley (Hordeum vulgare) & 4.24 \\
Wheat (Triticum aestivum) & 4.24 \\
Corn (Zea mays) & 4.24 \\
Silicon (as an excipient for hair and nails) & 4.10 \\
Natural isoflavones complex & 1.80 \\
Vegetable magnesium stearate & 0.40 \\
\hline
\end{tabular}

content, a natural isoflavones complex, buckwheat (Fagopyrum esculentum), black oat (Avena sativa), malt (Semen hordei vulgaris germinatum), barley (Hordeum vulgare), rye (Secale cereale), wheat (Triticum aestivum), corn (Zea mays), and dietary fiber. Exact ingredients of the product, as specified by the manufacturer, are given in Table 1.

\section{Discussion}

Vaginal bleeding is not uncommon in post-menopausal women and occurs in approximately $4-11 \%$ of women who have reached menopause $[9,10]$. The incidence of bleeding appears to correlate with time since menopause, with the likelihood of bleeding decreasing over time [10]. Recurrence of bleeding is very common in the time immediately after menopause, being the 12 months of amenorrhea after what is currently defined as the final menstrual period, declining to low frequencies more than 3 years after the final menstrual period [10]. The differential diagnosis of bleeding in post-menopausal women can include endometrial cancer, polyps, leiomyomata uteri (fibroids), and infection, among others. Endometrial hyperplasia may manifest clinically as uterine bleeding; however, since post-menopausal women should be estrogen deficient, endometrial hyperplasia at this time is abnormal and should be further investigated [9]. Postmenopausal hormone therapy can be a cause of endometrial hyperplasia and subsequent post-menopausal bleeding [11]. Soy and other phytoestrogens in large doses may be associated with stimulation of the endometrial lining, as has also been described by the Netherlands Pharmacovigilance Centre Lareb in a previous case series [7]. A randomized trial of 376 post-menopausal women who received soy versus placebo over a 5-year period showed that the occurrence of endometrial hyperplasia was significantly higher in the group receiving soy (3.37 vs. $0 \%$ ) [12].

In addition to soy, other plants have phytoestrogen properties. Hops are the female flowers (seed cones, strobiles) of the hop species Humulus lupulus $L$. The principal estrogen from hops is the 1:1 racemate, $( \pm)$-8-prenylnaringenin '8PN', also called hopein [13]. This is one of the most potent in vitro estrogenic substance known from the plant kingdom [5, 6, 13], with an estrogenic activity in vitro greater than that of other phytoestrogens such as coumestrol, genistein, and daidzein [14]. Nowadays, hops are used primarily for their bitter and aromatic properties in the manufacture of beer and are cultivated by the brewing industry. The content of 8-prenylnaringenine in beer varies widely. Most beer does not contain 8-prenylnaringenin in detectable quantities; the highest concentration found being $19.8 \mu \mathrm{g} \mathrm{L}^{-1}$ [15]. Although the percentage of hop in the product used in this case report is known $(41.40 \%)$, the 8-prenylnaringenin amount is not.

In addition to hop, the product also contains other plants that have phytoestrogenic activities. The plant lignans secoisolariciresinol (SEC) and matairesinol (MAT), which can be found in cereals, are converted to the metabolites enterodiol (ED) and enterolactone (EL), known as the mammalian lignans, in the gastrointestinal tract [16]. These compounds are bioactive as phytoestrogens because of their structural and functional similarity to $17 \beta$-estradiol [17]. In vitro, mammalian lignans may have both estrogenic and anti-estrogenic properties [16]. For cereals like oats (A. sativa), barley (H. vulgare), and rye ( $S$. cereale), the presence of lignans with phytoestrogenic properties has been described [16-18]. Malt is germinated cereal grains that have been dried in a process known as 'malting'. Various cereals are malted, though barley is the most common. Isoflavones are also found in cereals [17] and are an additional ingredient in this product. The exact nature of the 'natural isoflavones complex' described on the packaging of the product is unknown. Dietary flavonoids are also known for their antiplatelet activity, although the specific mechanisms by which this inhibition occurs has not been fully established. Inhibition of the platelet function through binding to the thromboxane A2 receptor has been described [19]. It is possible that all the ingredients with phytoestrogenic properties in the product could have had an additional effect to each other in causing the endometrial proliferation and subsequent vaginal hemorrhage. Estrogenic activity of the product was found in an ER assay with $17-\beta$-estradiol as a comparator by the company PhytoGeniX, which is a spin off contract research organization originating from the University of Utrecht (Department of Medicinal Chemistry, Faculty of 
Pharmacy) in the Netherlands [20]. The following is stated on the products' website (http://www.menocool.nl): "Only in the event that your uterus is removed, the starting dose is suitable for use indefinitely".

In Europe, products marketed as dietary supplements are loosely regulated as compared with medicines. This phytotherapeutic product is not officially registered through the Dutch Medicines Evaluation Board, but is sold as a food supplement, which falls under the jurisdiction of the Dutch Netherlands Food and Consumer Product Safety Authority (NVWA). The Commodities Act requires that these products are safe, but no mandatory safety testing takes place before they come on the market. Pharmacovigilance systems for registered drugs are well-defined. For food supplements, although they can contain pharmacologically active ingredients, such systems ('nutrivigilance') are less developed [21]. For pharmacovigilance, engaging consumer reports can be especially helpful in the recognition of 'blind spots' such as adverse reactions caused by (adulterated) herbal product and counterfeit medicines [22, 23]. In addition, awareness among healthcare professionals that patients can use herbal drugs or other products, bought without a prescription, is important.

With products bought over the internet, there is always a chance that the product is adulterated with conventional medicines. However, we deem it unlikely that this company has adulterated the herbal product with Western medicines. The product itself is compounded by DuSart Pharma (Katwijk, the Netherlands). For the department 'dry formulations' (tablets and capsules) DuSart Pharma adheres to the Pharma GMP regimen of nutritional supplements in accordance with a quality guideline issued by the European Federation of Associations of Health Product Manufactures (EHPM). DuSart Pharma complies with the Hazard Analysis and Critical Control Points (HACCP) requirements [24, 25]. Also, the owner of the company selling the product, among other herbal products such as a natural breast size enhancer, has been featured in both national and local newspapers in the Netherlands [26-28], and a skeptical article about their products was published in a Dutch medical journal [29]. A complaint about MenoCool ${ }^{\circledR}$ was also filed with the Dutch Advertising Code Committee. This was upheld and the manufacturer had to remove some of the health claims from the product's website [28].

A limitation of this case description is that some of the characteristics of the herbal product, as recommended in the CONSORT (Consolidated Standards of Reporting Trials) statement [30], are unknown to the authors. Since Lareb received spontaneous reports on the MenoCool ${ }^{\circledR}$ tablets and did not investigate the products in a trial setting, the authors have no information on what parts of the plants were used in this product. From a Dutch newspaper article, we know some limited details on the production process by
DuSart Pharma for products they made for Standby Vital $\mathrm{BV}$. The described production process, at the time of publication of the article, was rather simple: plant materials were ground and the created thick paste was used to press tablets [27]. The manufacturer of the product declares that it consists of $100 \%$ plant materials. Based on a visual inspection of the tablets, we presume that the tablets indeed consist of pressed plant materials. However, the Netherlands Pharmacovigilance Centre Lareb has not performed any qualitative testing on the product.

\section{Conclusion}

Based on the described cases and five earlier case reports to the Dutch pharmacovigilance center, we suggest a causal relation between vaginal bleeding due to endometrial proliferation after menopause associated with the use of this hop-containing product. A Naranjo assessment score of 5 was obtained for both case A and B, indicating a probable relationship between the vaginal hemorrhage and endometrial proliferation and their use of the suspect drug. Phytoestrogenic products for relief of menopausal symptoms are available as over-the-counter preparations, and consumers often mistakenly believe that they do not cause adverse drug reactions. In the differential diagnosis, it is important to be aware that the use of a dietary supplement or an herbal drug with phytoestrogenic properties may be a possible cause of post-menopausal bleeding.

Acknowledgments Florence van Hunsel, Sonja van de Koppel, and Eugene van Puijenbroek declare that they have no conflicts of interest.

No financial support was received for the conduct of this study or preparation of this manuscript.

Written informed consent was obtained from each of the patients for the publication of these case reports. Copies of the consents may be requested for review from the corresponding author.

Open Access This article is distributed under the terms of the Creative Commons Attribution-NonCommercial 4.0 International License (http://creativecommons.org/licenses/by-nc/4.0/), which permits any noncommercial use, distribution, and reproduction in any medium, provided you give appropriate credit to the original author(s) and the source, provide a link to the Creative Commons license, and indicate if changes were made.

\section{References}

1. Rossouw JE, Anderson GL, Prentice RL, LaCroix AZ, Kooperberg C, Stefanick ML, et al. Risks and benefits of estrogen plus progestin in healthy postmenopausal women: principal results From the Women's Health Initiative randomized controlled trial. JAMA. 2002;288(3):321-33.

2. Poluzzi E, Piccinni C, Raschi E, Rampa A, Recanatini M, De PF. Phytoestrogens in postmenopause: the state of the art from a 
chemical, pharmacological and regulatory perspective. Curr Med Chem. 2014;21(4):417-36.

3. Nettekoven M. Menopauze vaker met hormonen te lijf, Ondergebruik is onnodig. Pharm Weekbld. 2012;147(5):14-17.

4. Kurzer MS. Phytoestrogen supplement use by women. J Nutr. 2003;133(6):1983S-6S.

5. Milligan S, Kalita J, Pocock V, Heyerick A, De CL, Rong H, et al. Oestrogenic activity of the hop phyto-oestrogen, 8-prenylnaringenin. Reproduction. 2002;123(2):235-42.

6. Overk CR, Yao P, Chadwick LR, Nikolic D, Sun Y, Cuendet $\mathrm{MA}$, et al. Comparison of the in vitro estrogenic activities of compounds from hops (Humulus lupulus) and red clover (Trifolium pratense). J Agric Food Chem. 2005;53(16):6246-53.

7. van Hunsel FP, Kampschoer P. Postmenopausal bleeding and dietary supplements: a possible causal relationship with hop- and soy-containing preparations. Ned Tijdschr Geneeskd. 2012;156(41):A5095.

8. Micromedex ${ }^{\circledR} 1.0$ (Healthcare Series). Detailed evidence-based information (DRUGDEX ${ }^{\circledR}$ ) norethisterone. http://www. micromedexsolutions.com/. 2015 [cited 19 Mar 2015].

9. UpToDate ${ }^{\circledR}$. Postmenopausal uterine bleeding. http://www. uptodatecom/contents/postmenopausal-uterine-bleeding?source= machineLearning \&search $=$ postmenopausal+bleeding \& selectedTitle $=1 \%$ 7E33\&sectionRank=1\&anchor=H15\#H15. 2015 [cited 1 Feb 2015]. Available from: http://www.uptodate.com.

10. Astrup K, Olivarius NF. Frequency of spontaneously occurring postmenopausal bleeding in the general population. Acta Obstet Gynecol Scand. 2004;83(2):203-7.

11. Furness S, Roberts H, Marjoribanks J, Lethaby A. Hormone therapy in postmenopausal women and risk of endometrial hyperplasia. Cochrane Database Syst Rev. 2012;8:CD000402.

12. Unfer V, Casini ML, Costabile L, Mignosa M, Gerli S, Di Renzo GC. Endometrial effects of long-term treatment with phytoestrogens: a randomized, double-blind, placebo-controlled study. Fertil Steril. 2004;82(1):145-8.

13. Chadwick LR, Pauli GF, Farnsworth NR. The pharmacognosy of Humulus lupulus L. (hops) with an emphasis on estrogenic properties. Phytomedicine. 2006;13(1-2):119-31.

14. Milligan S, Kalita J, Pocock V, Heyerick A, De CL, Rong H, et al. Oestrogenic activity of the hop phyto-oestrogen, 8-prenylnaringenin. Reproduction. 2002;123(2):235-42.

15. Tekel' J, De KD, Rong H, Daeseleire E, Van PC. Determination of the hop-derived phytoestrogen, 8-prenylnaringenin, in beer by gas chromatography/mass spectrometry. J Agric Food Chem. 1999;47(12):5059-63.
16. Meagher LP, Beecher GR. Assessment of data on the lignan content of foods. J Food Compost Anal. 2000;13(6):935-46.

17. Kuhnle GG, Dell' aquila C, Aspinall SM, Runswick SA, Mulligan AA, Bingham SA. Phytoestrogen content of cereals and cerealbased foods consumed in the UK. Nutr Cancer. 2009;61(3):302-9.

18. Ososki AL, Kennelly EJ. Phytoestrogens: a review of the present state of research. Phytother Res. 2003;17(8):845-69.

19. Guerrero JA, Lozano ML, Castillo J, Benavente-Garcia O, Vicente V, Rivera J. Flavonoids inhibit platelet function through binding to the thromboxane A2 receptor. J Thromb Haemost. 2005;3(2):369-76.

20. PhytoGeniX. PhytoGeniX projects-Menocool. http://www. phytogenixnl/the-company/phytogenix-projects/. 2014 [cited 8 Jan 2015]. Available from: http://www.phytogenix.nl.

21. Schmitz SM, Lopez HL, MacKay D. Nutravigilance: principles and practices to enhance adverse event reporting in the dietary supplement and natural products industry. Int J Food Sci Nutr. 2014;65(2):129-34.

22. Walji R, Boon H, Barnes J, Austin Z, Welsh S, Baker GR. Consumers of natural health products: natural-born pharmacovigilantes? BMC Complement Altern Med. 2010;10:8.

23. van Hunsel F, Harmark L, Pal S, Olsson S, van Grootheest K. Experiences with adverse drug reaction reporting by patients: an 11-country survey. Drug Saf. 2012;35(1):45-60.

24. DuSart Pharma. DuSart Pharma website. http://www. dusartpharma.com/Default?lang=EN. 2015 [cited 28 July 2015]. Available from: http://www.dusartpharma.com.

25. USA Food and Drug Administration (FDA). Hazard Analysis \& Critical Control Points (HACCP). http://www.fda.gov/Food/ GuidanceRegulation/HACCP/. 2015 [cited 28 Sept 2015]. Available from: http://www.fda.gov/.

26. Scholtens B. Studie naar borstvergrotende pil. Algemeen Dagblad (AD). 6 Dec 2003. Sect. Geld $>$ producten.

27. van Calmthout M. De Wonderhop. De Volkskrant. 6 Jan 2001. Sect. Archive.

28. Unknown journalist. Online gevecht over voedingssupplement. Dagblad de Limburger. 8 Nov 2012. Sect. Economy.

29. Kievits F, Adriaanse MT. Wonderbaarlijke borstvergroting. Ned Tijdschr Geneeskd. 2003;147:2598-9.

30. Gagnier JJ, Boon H, Rochon P, Moher D, Barnes J, Bombardier C. Reporting randomized, controlled trials of herbal interventions: an elaborated CONSORT statement. Ann Intern Med. 2006;144(5):364-7. 